\title{
PERANCANGAN APIKASI MOBILE E-COMMERCE BERBASIS ANDROID PADA TOKO SEMBAKO BERKAH JAYA DI ERA COVID-19
}

\author{
Akhmad Abdul Aziz dan Fitrah Satrya Fajar K ${ }^{2}$ \\ akhmadabdulaziz337@gmail.com ${ }^{1}$ \\ Fitrah@uika-bogor.ac.id ${ }^{2}$ \\ Teknik Informatika, Fakultas Teknik \&Sains, Universitas Ibn Khaldun Bogor ${ }^{1,2}$
}

\begin{abstract}
ABSTRAK
Toko Sembako Berkah Jaya adalah salah satu toko yang menjual berbagai sembako yang berada dikota Bogor, beralamat di Jl.Asrama Palad Blok B No.10, RT.2/RW.5 Cirimekar, Cibinong. Sistem yang sedang berjalan saat ini masih dinilai belum efektif dalam hal pemasaran apa lagi dimasa pandemi seperti ini, pelanggan selalu menginginkan kemudahan ataupun kecepatan informasi yang relevan untuk memudahkan segala aktivitasnya tanpa harus keluar rumah, salah satunya pemesanan ataupun pembelian sembako pada Toko Sembako Berkah Jaya. Penelitian ini bertujuan membantu pelanggan agar dapat berbelaaknja dimana pun dan kapan pun yang diinginkan secara flexible tanpa harus keluar rumah dan pergi ketoko tersebut. Jadi maksud dari penelitian ini untuk mengurangi terjadinya penularan covid-19 maka saya ingin membuat perancangan aplikasi mobile e-commerce berbasis android untuk penjualan sembako pada Toko Sembako Berkah Jaya. Dalam membangun sistem ini penulis menggunakan metode prototype dimana teknik pengumpulan data yang dilakukan adalah wawancara dan studi pustaka. Sedangkan dalam membantu analisis dan perancangan sistem menggunakan Unified Modeling Language dengan dibuatnya aplikasi mobile e-commerce berbasis android untuk penjualan sembako pada Toko Sembako Berkah Jaya dapat memudahkan pelanggan dalam melakukan transaksi pemesanan dan mendapatkan informasi tentang Toko Sembako Berkah Jaya dan mengurangi terjadinya penularan covid-19.
\end{abstract}

Kata Kunci: android, aplikasi, mobile, e-commerce, prototype.

\section{PENDAHULUAN}

\section{Latar Belakang}

Covid-19 merupakan penyakit menular yang berpotensi menimbulkan kedaruratan kesehatan masyarakat. Urgensi pembentukan aturan terkait dengan pencegahan Covid-19 ini wajib dibentuk dalam Peraturan Pemerintah dan Peraturan Menteri Kesehatan karena kedua peraturan tersebut merupakan peraturan pelaksanaan daripada Undang-Undang Nomor 6 Tahun 2018 tentang Kekarantinaan Kesehatan. Covid-19 juga membawa perubahan terhadap berbagai pola kehidupan yang terjadi di masyarakat. Simpang siur berita terkait proses penularannya masih menjadi momok bagi Sebagian masyarakat. Sehingga banyak masyarakat yang takut untuk keluar rumah untuk memenuhi kebutuhan hidupnya. Toko Sembako Berkah Jaya adalah salah satu toko yang menjual berbagai sembako yang berada dikota Bogor, Jl.Asrama Palad Blok B No.10, RT.2/RW.5 Cirimekar, Cibinong. 
Terjadi penurunan pembelian pada Toko Sembako Berkah Jaya akibat banyak warga sekitar yang khawatir dengan penularan Covid-19. Untuk itu demi memberikan kemudahan kepada para pelanggan Toko Sembako Berkah Jaya, dibutuhkan sebuah sarana pembelanjaan online. Hal ini dibutuhkan sehingga pelanggan tidak perlu keluar rumah untuk pergi ketoko sembako dan dapat menghindari terjadinya penularan Covid19 dikomplek tersebut. Maka dibutuhkan suatu aplikasi yang dapat mempermudah dalam transaksi pemesanan sembako untuk kebutuhan sehari-hari, khususnya melalui media perangkat bergerak sehingga lebih efektif dan efisien. Begitu juga dalam memenuhi kebutuhan rumah tangga mereka [1].

Dengan keunggulan yang dimiliki Android maka muncul gagasan untuk merancang dan membuat aplikasi mobile E-commerce berbasis Android untuk penjualan sembako pada Toko Sembako Berkah Jaya diera Covid-19 guna menyelesaikan masalah, maka penulis berinisiatif untuk merancang dan membuat media yang berguna untuk melakukan transaksi pemesanan dan penjualan barang serta dapat membantu memenuhi kebutuhan khusunya bagi pengguna Android dan yang terdampak Covid-19 juga ditempat lain [2].

Android dalam bentuk smartphone, merupakan solusi yang dapat memberikan jawaban kekurangan sistem yang sudah ada. Aplikasi dalam bentuk smartphone ini mempunyai beberapa kelebihan dalam penggunaanya dan tidak menghabiskan waktu. Dengan menggunakan aplikasi ini diharapkan dapat membantu pelanggan untuk memilih atau memesan sebuah barang kebutuhan rumah tangga pada Toko Sembako Berkah Jaya [3].
Dengan menggunakan aplikasi ini diharapkan pelanggan bisa terbantu untuk mendapatkan informasi yang ada pada Toko Sembako Berkah Jaya dan dapat berjalan pada perangkat smartphone berbasis Android.

\section{Rumusan Masalah}

Beberapa rumusan masalah dari penelitian ini adalah :

1. Bagaimana membantu Toko Berkah Jaya agar dapat Kembali meningkatkan pemasukkannya di tengah-tengah kondisi Covid-19?

2. Bagaimana membantu masyakarat sekitar toko agar dapat berbelanja Sembako tanpa harus keluar rumah?

\section{Tujuan}

Tujuan dari penelitian saya adalah merancang sebuah sistem pembelian online berbasis Android untuk pihak toko ataupun pihak pembeli. Sehingga memudahkan pembeli untuk membeli Sembako dan tidak perlu keluar rumah, guna mengurangi dampak penularan Covid-19 di daerah perumahan Jl.Asrama Palad Blok B No.10, RT.2/RW.5 Cirimekar, Cibinong.

\section{Urgensi Penelitian}

Karena wabah covid-19 warga perumahan komlpek salak takut keluar rumah untuk berpergian kemana mana bahkan ketoko untuk berbelanja bahan pokok sehari-hari. Maka dari itu penulis membuat penelitian Perancangan Aplikasi Mobile E-commerce Berbasis Android Pada Toko Sembako Berkah Jaya Diera Covid-19, guna membantu warga perumahan komplek salak dalam hal berbelanja bahan pokok/ sembako diperumahan Jl.Asrama Palad Blok B No.10, RT.2/RW.5 Cirimekar, Cibinong.

\section{Manfaat}

Beberapa manfaat dari kerja praktik ini adalah: 
1. Jika sistem ini dikembangkan secara penuh maka sistem ini akan dapat membantu warga perumahan Jl.Asrama Palad Blok B No.10, RT.2/RW.5 Cirimekar, Cibinong dalam berbelanja bahan dapur/ sembako dan tidak harus keluar rumah.
2. Dapat mencegah tertular dari covid19 dan mengindari/mengurangi dampak penularan covid-19 diperumahan Jl.Asrama Palad Blok B No.10, RT.2/RW.5 Cirimekar, Cibinong.

\section{METODE PENELITIAN}

Dalam penulisan penelitian KKNGTM ini, metode pengembangan sistem yang digunakan untuk analisis sistem yaitu metode prototype [4].

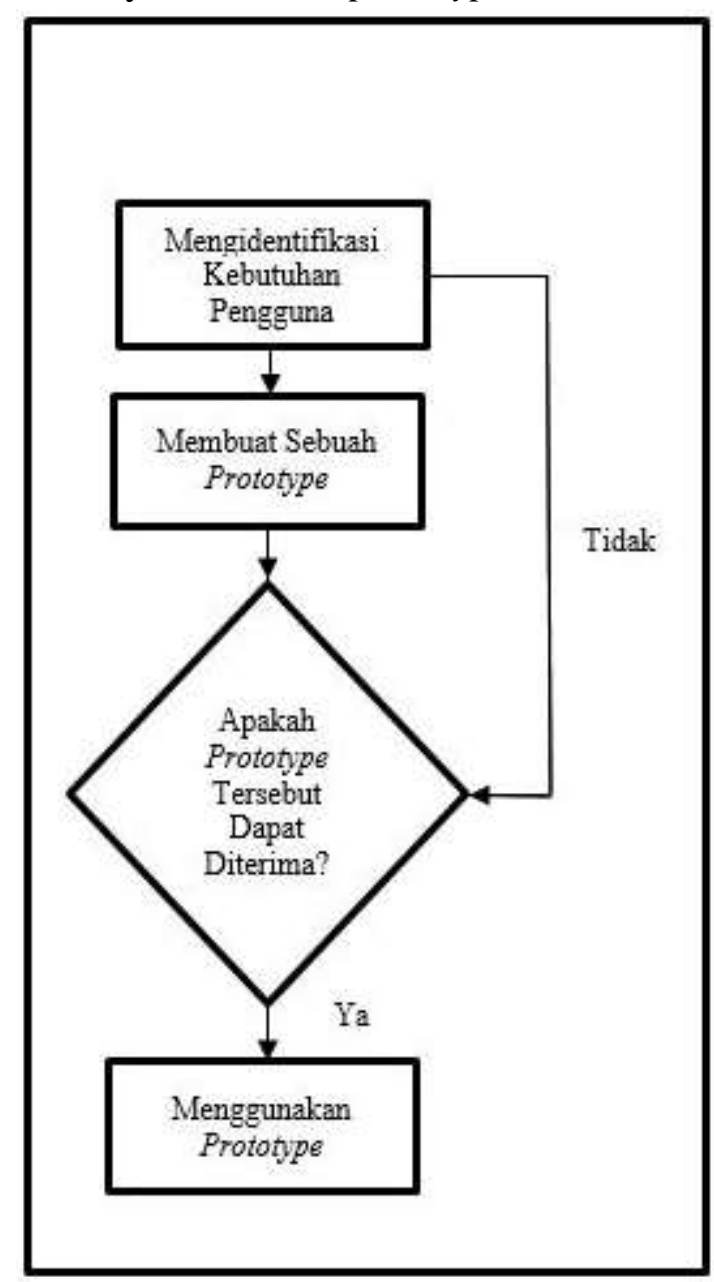

Gambar 1. Metode Prototype

\section{HASIL DAN PEMBAHASAN}

\section{Tahap Identifikasi Masalah}

Permasalahan yang terjadi pada Toko Sembako Berkah Jaya ini adalah salah satunya pelanggan ingin menginginkan kemudahan ataupun kecepatan dalam pemesanan barang, yang biasa dilakukan pada pihak Toko Sembako Berkah Jaya ini belum menggunakan sistem yang terkomputerisasi, Jadi pelanggan masih membeli dan datang langsung sehingga 
membuat pelanggan yang ingin melakukan pembelian dan pembayaran menunggu lama, serta permasalahan lainnya data penjualan tidak tertata dengan rapih sehingga mempersulit bagian admin dalam proses pembukuan yang jelas.

Aplikasi pemesanan sembako pada Toko Sembako Berkah Jaya Berbasis Android ini mempunyai sebuah arsitektur pelanggan yang menggunakan smartphone android melakukan permintaan data ke $D B M Y S Q L$ melalui apache web server, begitupun sebaliknya. Lalu Admin pun juga melakukan permintaan data ke $D B M Y S Q L$ melalui apache \& web server begitupun sebaliknya.

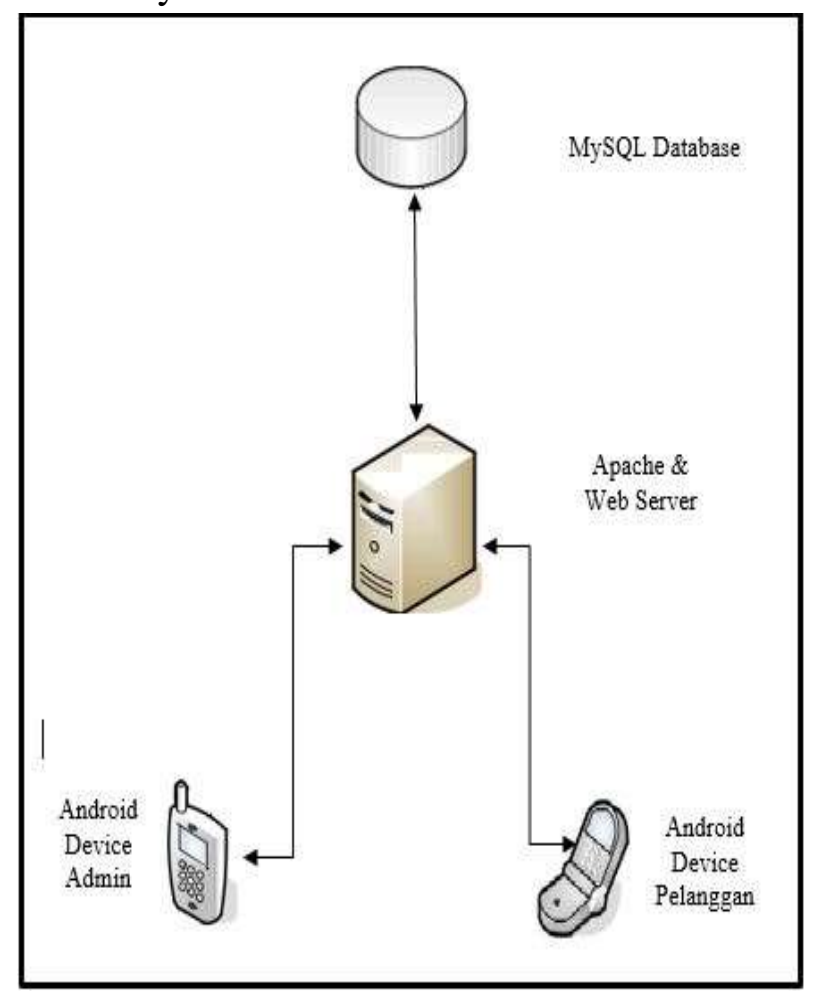

Gambar 2. Arsitektur

Perancangan model digunakan untuk dapat menggambarkan sistem berjalan. Perancangan desain sistem merupakan proses masalah yang bertujuan untuk membangun sistem yang dapat memenuhi kebutuhan.

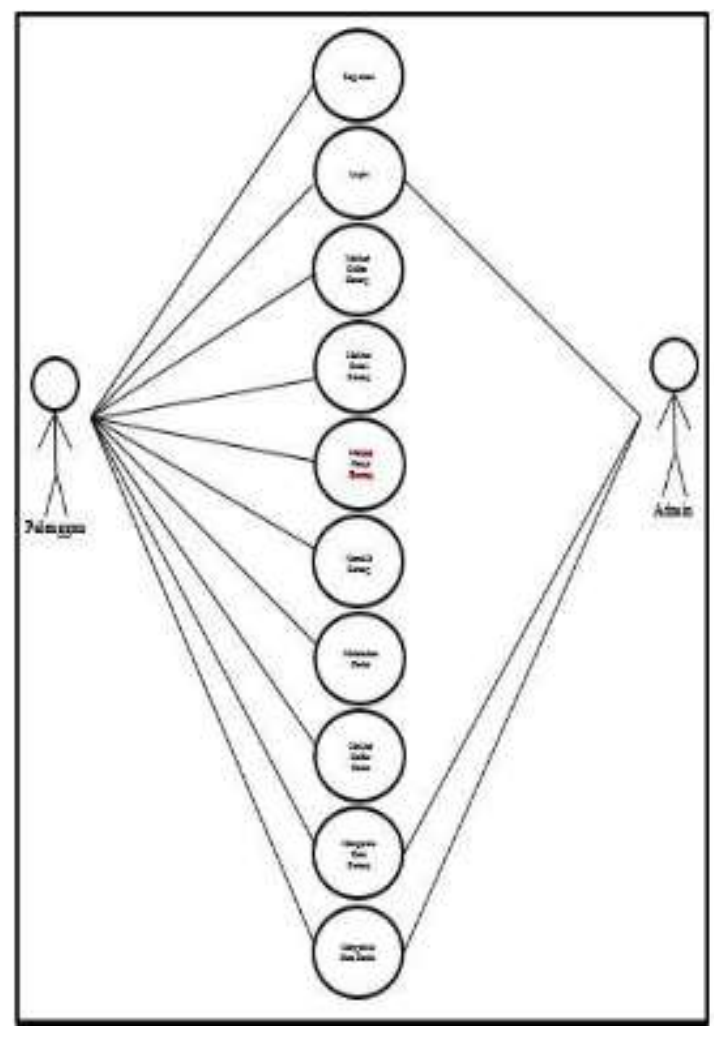

Gambar 3. Sistem Berjalan

\section{Desain I/O}

Desain input/ouput menjelaskan kepada pengguna desain sementara yang berfokus pada penyajian :

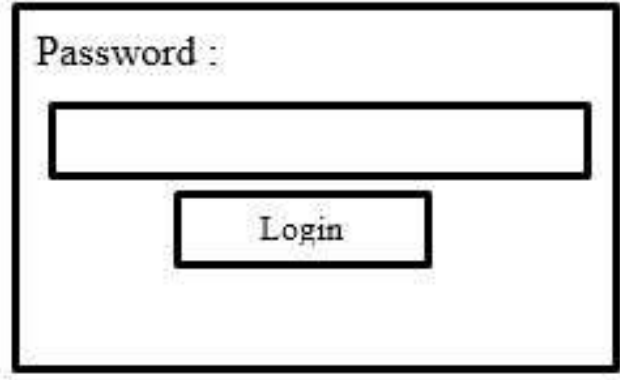

Gambar 4. Tampilan Login Admin

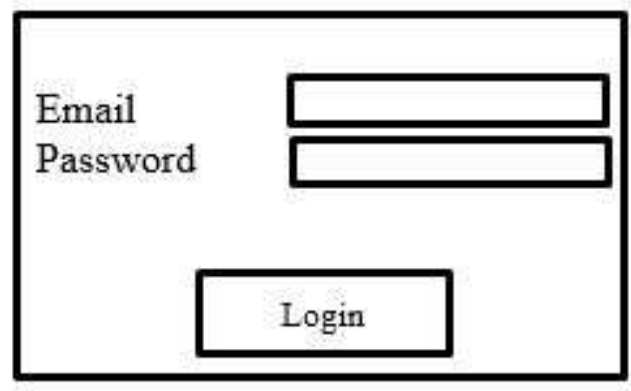

Gambar 5. Tampilan Login Pelanggan 


\section{Pengujian}

Pada tahap ini, sistem akan diuji fungsi fungsinya terhadap aplikasi mobile $e$ commerce. Evaluasi ini menggunakan metode blackbox, yang memastikan bahwa aplikasi ini sesuai dengan tujuan dari customer dan dapat beroperasi dengan baik, berikut hasil dari pengujian sistem melalui blackbox :

\begin{tabular}{|c|c|c|c|}
\hline Proses & Fungsi & $\begin{array}{l}\text { Hasil Yang } \\
\text { Diterapkan }\end{array}$ & Hasil \\
\hline $\begin{array}{l}\text { Registrasi } \\
\text { Customer }\end{array}$ & $\begin{array}{l}\text { Memberikan } \\
\text { data } \\
\text { pelanggan } \\
\text { untuk proses } \\
\text { pendaftaran }\end{array}$ & $\begin{array}{l}\text { Halaman } \\
\text { menu } \\
\text { registrasi } \\
\text { ditampilkan } \\
\text { ketika } \\
\text { pelanggan } \\
\text { belum } \\
\text { mendaftar } \\
\text { menjadi } \\
\text { member. }\end{array}$ & Selesai \\
\hline $\begin{array}{l}\text { Login } \\
\text { Customer }\end{array}$ & $\begin{array}{l}\text { Membantu } \\
\text { pelanggan } \\
\text { dalam masuk } \\
\text { kemenu } \\
\text { utama. }\end{array}$ & $\begin{array}{l}\text { Login } \\
\text { berhasil } \\
\text { apabila user } \\
\text { dan } \\
\text { password } \\
\text { benar }\end{array}$ & Sesuai \\
\hline $\begin{array}{l}\text { Menu } \\
\text { Utama }\end{array}$ & $\begin{array}{l}\text { Menampilkan } \\
\text { menu utama } \\
\text { yang } \\
\text { berisikan } \\
\text { kategori,detail } \\
\text { barang dan } \\
\text { keranjang } \\
\text { pembelian }\end{array}$ & $\begin{array}{l}\text { Halaman } \\
\text { menu utama } \\
\text { ditampilkan }\end{array}$ & Sesuai \\
\hline
\end{tabular}

Gambar 6. Tabel Blackbox

1. Halaman login admin

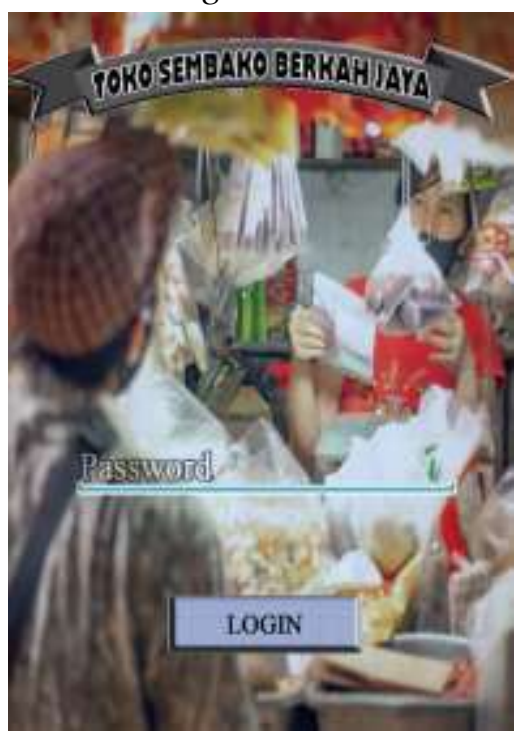

Tampilan halaman login admin ini adalah halaman yang dikhususkan untuk admin/owner toko, ketika ingin login hanya memasukkan password 
yang telah dibuat oleh owner toko tersebut.

2. Data Input Barang

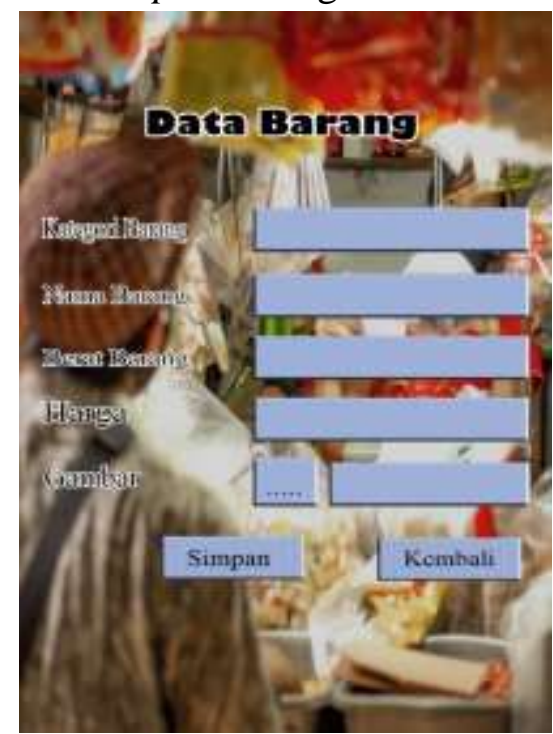

Tampilan data input barang ini adalah berfungsi pada saat owner toko ingin measukkan barang yang ingin dijual ditokonya.

\section{Halaman Login Pelanggan}

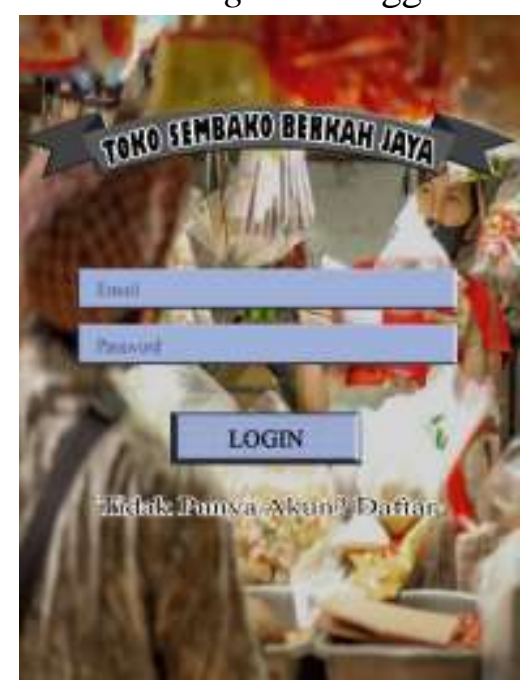

Tampilan halaman login pelanggan ini dikhususkan untuk pelanggan yang telah mempunyai akun untuk masuk/login keaplikasi toko dan membeli sembako yang dijual.
4. Register Pelanggan

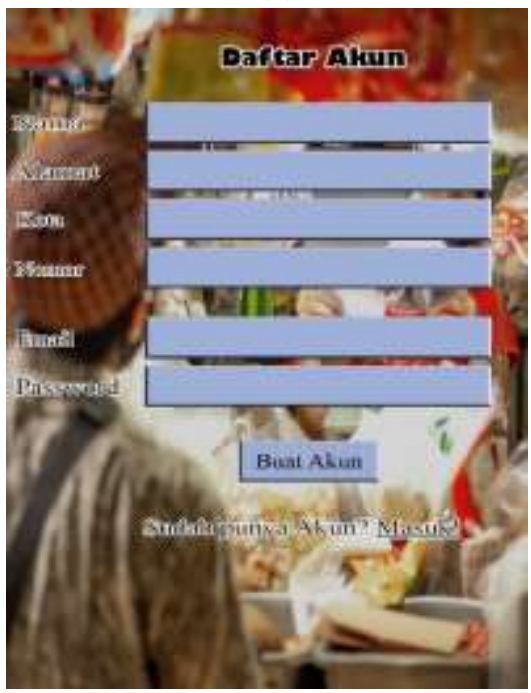

Tampilan register pelanggan ini dikhusukan untuk pelanggan yang tidak mempunyai akun untuk masuk ke apikasi toko, maka pelanggan harus membuat akun terlebih dahulu untuk masuk keaplikasi toko.

5. Halaman Utama

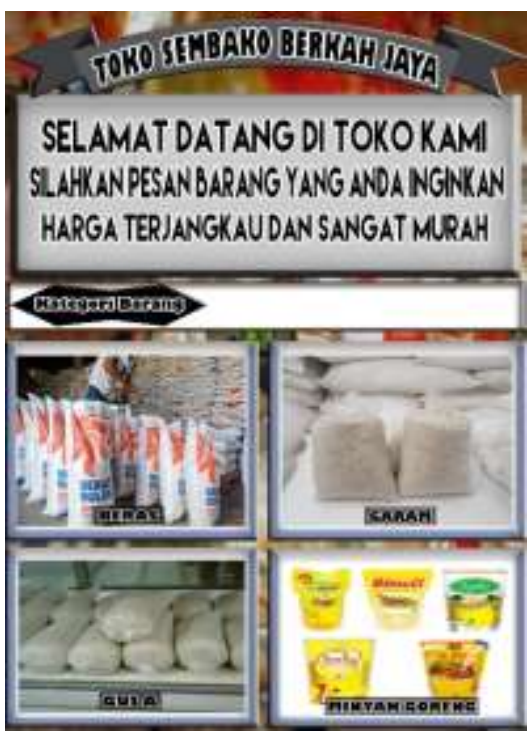

Tampilan halaman utama ini adalah tampilan utama dari toko Ketika pelanggan sudah login/masuk kedalam aplikasi toko. 
6. Daftar Barang Perkategori

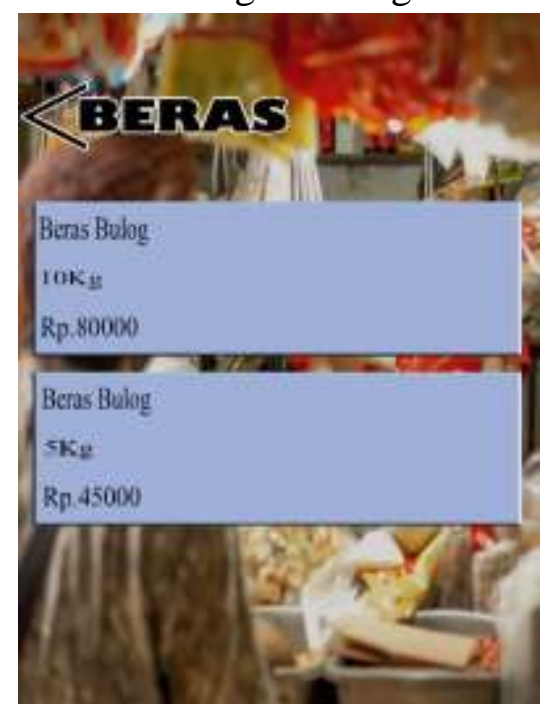

Tampilan daftar barang perkategori adalah tampilan rincian barang yang dijual ditoko.

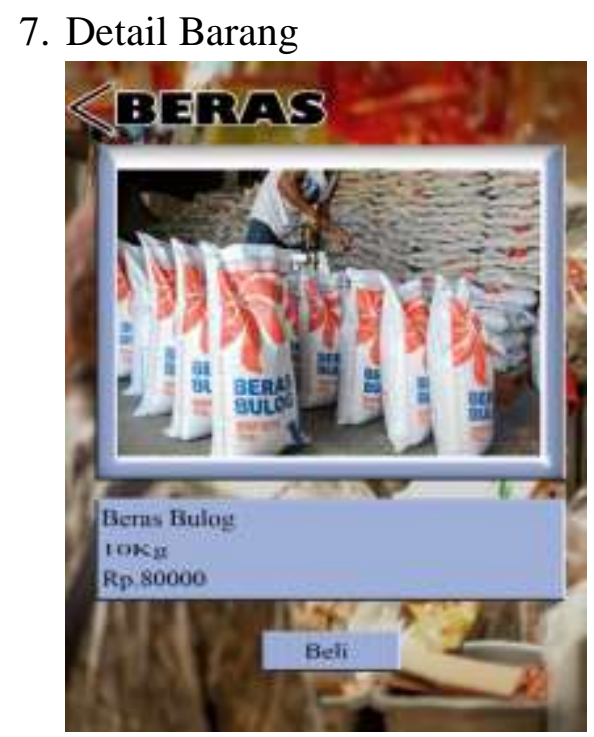

\section{KESIMPULAN}

Dari hasil pengujian aplikasi, dapat disimpulkan beberapa hal sebagai berikut :

1. Dari hasil perancangan ini didapatkan berbagai perancangan sistem yang dapat dikembangkan untuk tahap selanjutnya untuk membantu Pelanggan Toko Sembako Berkah Jaya agar dapat mengetahui informasi barang dan detail barang yang diinginkan oleh
Tampilan detail barang adalah tampilan detail barang yang dijual ketika memilih barang apa yang mau dibeli dirincian barang.

8. Pembelian Barang

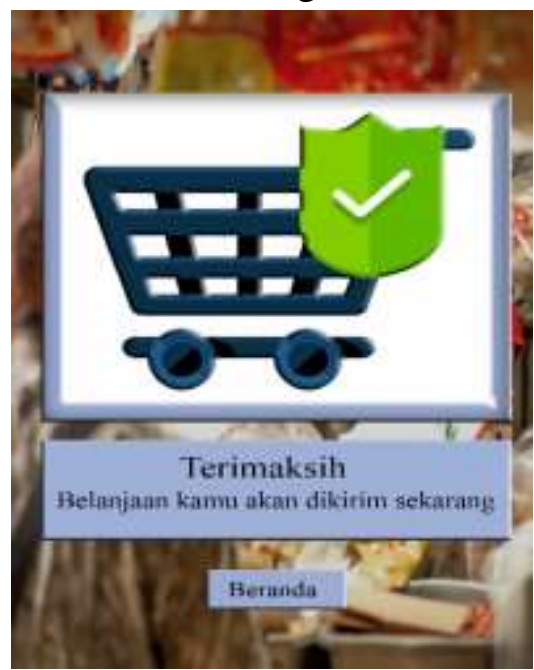

Tampilan pembelian barang ini adalah tampilan ketika pelanggan membeli salah satu barang setelah melihat detail barang yang ada didalam aplikasi toko.

pelanggan, tanpa pelanggan harus datang langsung pada Toko Sembako Berkah Jaya.

2. Pembuatan aplikasi Android ini menjadi salah satu solusi untuk memberikan kemudahan kepada pelanggan Toko Sembako Berkah Jaya untuk mengetahui informasi barang yang ter-update untuk setiap minggunya. 
3. Dengan adanya apliaksi ini, pelanggan dapat terhindari dari

\section{DAFTAR PUSTAKA}

Telaumbanua, D. (2020). Urgensi Pembentukan Aturan Terkait

Pencegahan Covid-19 Di Indonesia. QALAMUNA: Jurnal Pendidikan, Sosial, dan Agama, 12(1), 59-70.

Berbasis Android Pada Kelompok Swadaya Masyarakat Desa Margakaya Pringsewu. Jurnal Ilmiah Ilmu Komputer Fakultas Ilmu Komputer Universitas Al Asyariah Mandar, 4(1), 8-12.

Syarifudin, A. (2019). Perancangan Sistem Informasi Pengajuan dan Pelaporan penularan wabah Covid-19 karena pembelian tidak harus keluar rumah.

\author{
Pembayaran Tunjangan Kinerja \\ Kementerian Keuangan \\ Menggunakan Metode \\ Prototype. Jurnal Sisfokom (Sistem \\ Informasi dan Komputer), 8(2), 149- \\ 158.
}

Sitepu, A. I. B., \& Tanjung, D. Y. H. (2020). Rancang Bangun Aplikasi Pemesanan dan Penjualan Berbasis Web dan Android pada Toko YT. Wall Interior. Jurnal Mahasiswa Fakultas Teknik dan Ilmu Komputer, 1(1), 816-828. 